IZA DP No. 7186

Persistence Bias and the Wage-Schooling Model

Corrado Andini

January 2013 


\title{
Persistence Bias and the Wage-Schooling Model
}

\author{
Corrado Andini \\ Universidade da Madeira, \\ CEEApIA and IZA
}

\author{
Discussion Paper No. 7186 \\ January 2013
}

IZA
P.O. Box 7240
53072 Bonn
Germany

Phone: +49-228-3894-0

Fax: +49-228-3894-180

E-mail: iza@iza.org

Any opinions expressed here are those of the author(s) and not those of IZA. Research published in this series may include views on policy, but the institute itself takes no institutional policy positions. The IZA research network is committed to the IZA Guiding Principles of Research Integrity.

The Institute for the Study of Labor (IZA) in Bonn is a local and virtual international research center and a place of communication between science, politics and business. IZA is an independent nonprofit organization supported by Deutsche Post Foundation. The center is associated with the University of Bonn and offers a stimulating research environment through its international network, workshops and conferences, data service, project support, research visits and doctoral program. IZA engages in (i) original and internationally competitive research in all fields of labor economics, (ii) development of policy concepts, and (iii) dissemination of research results and concepts to the interested public.

IZA Discussion Papers often represent preliminary work and are circulated to encourage discussion. Citation of such a paper should account for its provisional character. A revised version may be available directly from the author. 
IZA Discussion Paper No. 7186

January 2013

\section{ABSTRACT}

\section{Persistence Bias and the Wage-Schooling Model}

This paper provides an expression for the bias of the OLS estimator of the schooling coefficient in a simple static wage-schooling model where earnings persistence is not accounted for. It is argued that the OLS estimator of the schooling coefficient is biased upward, and the bias is increasing with potential labor-market experience and the degree of earnings persistence. In addition, NLSY data are used to show that the magnitude of the persistence bias is non-negligible, and the bias cannot be cured by increasing the control set. Further, it is shown that disregarding earnings persistence is still problematic for the estimation of the schooling coefficient even if individual unobserved heterogeneity and endogeneity are taken into account. Overall, the findings support the dynamic approach to the estimation of wage-schooling models recently suggested by Andini (2012; 2013).

JEL Classification: $\quad \mathrm{C} 23, \mathrm{I} 21, \mathrm{~J} 31$

Keywords: $\quad$ schooling, wages, dynamic panel-data models

Corresponding author:

Corrado Andini

Universidade da Madeira

Campus da Penteada

9000-390 Funchal

Portugal

E-mail: andini@uma.pt 


\section{Introduction}

Since Griliches (1977), it is known that the Ordinary Least Squares (OLS) estimator of the schooling coefficient in a simple static wage-schooling model is biased i) upward due to the correlation between individual unobserved ability and schooling (ability bias) and ii) downward due to measurement errors in the schooling variable (attenuation bias).

Attempts to cure (reduce) both ability and/or attenuation bias have been based on extensions of the control set (to proxy unobserved error components and reduce the 'importance' of the error term), the use of better data (such as longitudinal data, to control for individual unobserved heterogeneity), Instrumental Variable (IV) estimation (to control for endogeneity), and combinations of these methods. As argued by Card (2001), IV estimates of the schooling coefficient are typically found to be bigger than OLS estimates and more imprecise.

While there are hundreds of studies dealing with ability and attenuation bias, to the best of our knowledge, no research has been so far conducted to highlight another important source of bias for the OLS estimator of the schooling coefficient in a simple wage-schooling model, the bias arising from the estimation of a static model which disregards earnings persistence. Let us label it as the 'persistence bias'.

Despite the fact that the above-referred bias has been introduced as a specific problem with the OLS estimation of the schooling coefficient in a static wage-schooling model, this paper will argue that the persistence bias should be interpreted as a general problem associated with the estimation of the schooling coefficient in a static wageschooling model, regardless of the estimator used. For instance, it will be argued that the standard static IV estimation is unable to solve the persistence-bias problem.

In particular, this paper provides the following three novel findings. First, it provides an expression for the bias of the OLS estimator of the schooling coefficient in a simple wage-schooling model where earnings persistence is not accounted for. It is argued that the OLS estimator of the schooling coefficient is biased upward, and the bias is increasing with potential labor-market experience and the degree of earnings persistence. Second, data from the National Longitudinal Survey of Youth (NLSY) are used to show that the magnitude of the persistence bias is non-negligible, and the bias cannot be cured by increasing the control set. Finally, it is shown that disregarding earnings persistence is still problematic for the estimation of the schooling coefficient even if individual unobserved heterogeneity and endogeneity are taken into account. The case of the Hausman-Taylor estimator is considered. 
In short, the standard cures for both ability and attenuation bias (based on extensions of the control set, models with individual unobserved heterogeneity, and treatments of endogeneity) are unable to solve the persistence-bias problem related to the estimation of static wage-schooling models.

Overall, the findings support the dynamic approach to the estimation of wageschooling models recently suggested by Andini (2012; 2013).

The paper is organized as follows. Section 2 provides an expression for the persistence bias of the OLS estimator for the schooling coefficient. Section 3 investigates the magnitude of the bias using US data on young male workers. Section 4 analyzes whether the bias can be somehow reduced by extending the control set. Section 5 highlights that disregarding earnings persistence is problematic even if unobserved heterogeneity and endogeneity are accounted for. In particular, the case of the Hausman-Taylor estimator is discussed. Section 6 concludes.

\section{Persistence bias}

This section provides an expression for the persistence bias of the OLS estimator of the schooling coefficient, under a set of simplifying hypotheses.

Let us consider a simple wage-schooling model. In particular, let us assume that the 'true' model is as follows:

$$
\mathrm{w}_{\mathrm{i}, \mathrm{s}+\mathrm{z}+1}=\alpha+\beta \mathrm{s}_{\mathrm{i}}+\rho \mathrm{w}_{\mathrm{i}, \mathrm{s}+\mathrm{z}}+\mathrm{u}_{\mathrm{i}, \mathrm{s}+\mathrm{z}+1} \text { for } \forall \mathrm{i}, \mathrm{s}+\mathrm{z} \text { with } \mathrm{s} \geq 1 \mathrm{z} \geq 0
$$

where $\mathrm{w}$ is logarithm of gross hourly wage, $\mathrm{s}$ is schooling years, $\mathrm{z}$ is years of potential labor-market experience, and $\mathrm{u}$ is an error term ${ }^{1}$. Hence the 'true' model is dynamic in the sense that past wages help to predict current wages.

In addition, let us assume that:

(A1)

$$
\operatorname{COV}\left(\mathrm{s}_{\mathrm{i}}, \mathrm{u}_{\mathrm{i}, \mathrm{s}+\mathrm{z}+1}\right)=0 \quad \forall \mathrm{i}, \mathrm{s}+\mathrm{z}
$$

$$
\operatorname{COV}\left(\mathrm{w}_{\mathrm{i}, \mathrm{s}+\mathrm{z}}, \mathrm{u}_{\mathrm{i}, \mathrm{s}+\mathrm{z}+1}\right)=0 \quad \forall \mathrm{i}, \mathrm{s}+\mathrm{z}
$$

${ }^{1}$ Following the standard Mincerian model, it is assumed that an individual starts working after leaving school. Schooling is assumed to be at least one year ( $s \geq 1$ ). Year $\mathrm{s}-1$ is the last year of the schooling life. That is, if an individual has just one year of schooling $(s=1)$, this schooling year has been completed during year $0(s-1=0)$. The first observed wage is observed in year $\mathrm{s}$. 
(A3) COV

$$
\operatorname{COV}\left(\mathrm{u}_{\mathrm{i}, \mathrm{s}+\mathrm{z}}, \mathrm{u}_{\mathrm{i}, \mathrm{s}+\mathrm{z}+1}\right)=0 \quad \forall \mathrm{i}, \mathrm{s}+\mathrm{z}
$$

(A4)

$$
\operatorname{COV}\left(\mathrm{u}_{\mathrm{i}, \mathrm{s}+\mathrm{z}}, \mathrm{u}_{\mathrm{j}, \mathrm{s}+\mathrm{z}}\right)=0 \quad \forall \mathrm{i} \neq \mathrm{j}, \mathrm{s}+\mathrm{z}
$$

(A5) $\mathrm{E}\left(\mathrm{u}_{\mathrm{i}, \mathrm{s}+\mathrm{z}+1}\right)=0$

$\forall \mathrm{i}, \mathrm{s}+\mathrm{z}$

(A6) $\operatorname{VAR}\left(\mathrm{u}_{\mathrm{i}, \mathrm{s}+\mathrm{z}+1}\right)=\theta^{2}$

$\forall \mathrm{i}, \mathrm{s}+\mathrm{z}$

(A7) $\operatorname{VAR}\left(\mathrm{s}_{\mathrm{i}}\right)=\sigma^{2}$

$\forall \mathrm{i}$

$$
\operatorname{COV}\left(s_{i}, \rho w_{i, s-1}+u_{i, s}\right)=0 \quad \forall i, s
$$

Assumption (A1) basically means that we exclude both ability and attenuation bias in order to focus on the persistence bias. Assumption (A2) is an additional condition required for the OLS estimator of model (1) to be consistent (it excludes the so-called Nickell bias). Of course, both these assumptions are unlikely to hold. However, we will discuss the implications of removing them later on. First, we will use these simplifying assumptions to make the first point of this paper, which is about the inconsistency of the OLS estimator for the schooling coefficient when the wage-schooling model does not take into account earnings persistence.

Assumptions from (A3) to (A7) are quite standard. Assumption (A8), instead, is not standard. It can be seen as an 'initial condition'. One may think at $\mathrm{w}_{\mathrm{i}, \mathrm{s}-1}$ as a reservation wage ${ }^{2}$ that every individual has in mind before leaving school, at time $s-1$. Yet, this wage is not observed. Hence, at time s, the error term in model (1) will be given by $\left(\rho \mathrm{w}_{\mathrm{i}, \mathrm{s}-1}+\mathrm{u}_{\mathrm{i}, \mathrm{s}}\right)$. It may well be the case that this reservation wage is correlated with $s_{i}$ as higher educated people are likely to have higher reservation wages. However, assumption (A8) excludes this possibility. The reason is simple and related to assumption (A1): at this stage, in order to focus on the OLS persistence bias, we exclude all sources of bias due to correlation between schooling and the error term in

\footnotetext{
${ }^{2}$ The idea of a reservation wage is compatible with the presence of self-selection into the labor market. However, in this paper, we do not deal with this important issue. We just consider the estimation of a wage equation where earnings persistence, individual unobserved heterogeneity and endogeneity matter.
} 
model (1). Again, we will discuss the implications of removing these simplifying assumptions later on.

Under the above hypotheses, a proof of the inconsistency of the OLS estimator applied to a simple static wage-schooling model is straightforward. In short, if the 'true' model is (1) but earnings persistence is disregarded and the following static model is estimated:

$$
\mathrm{w}_{\mathrm{i}, \mathrm{s}+\mathrm{z}+1}=\alpha+\beta \mathrm{s}_{\mathrm{i}}+\mathrm{e}_{\mathrm{i}, \mathrm{s}+\mathrm{z}+1}
$$

where $e_{i, s+z+1}=\rho w_{i, s+z}+u_{i, s+z+1}$

then, it is easy to show that:

(3) $p \lim \beta_{\text {OLS }}=\beta+\rho \frac{\operatorname{COV}\left(s_{i}, w_{i, s+z}\right)}{\operatorname{VAR}\left(s_{i}\right)}$

Knowing that $\operatorname{VAR}\left(\mathrm{s}_{\mathrm{i}}\right)=\sigma^{2}$, it is possible to focus on $\operatorname{COV}\left(\mathrm{s}_{\mathrm{i}}, \mathrm{w}_{\mathrm{i}, \mathrm{s}+\mathrm{z}}\right)$. In particular, it can be shown that:

(4)

$$
\begin{aligned}
& \operatorname{COV}\left(s_{i}, w_{i, s+z}\right)=\operatorname{COV}\left(s_{i}, \alpha+\beta s_{i}+\rho w_{i, s+z-1}+u_{i, s+z}\right)= \\
& =\beta \sigma^{2}+\rho \operatorname{COV}\left(s_{i}, w_{i, s+z-1}\right)=\beta \sigma^{2}+\rho \operatorname{COV}\left(s_{i}, \alpha+\beta s_{i}+\rho w_{i, s+z-2}+u_{i, s+z-1}\right)= \\
& =\beta \sigma^{2}+\rho\left[\beta \sigma^{2}+\rho \operatorname{COV}\left(s_{i}, w_{i, s+z-2}\right)\right]=\beta \sigma^{2}+\rho \beta \sigma^{2}+\rho^{2} \operatorname{COV}\left(s_{i}, w_{i, s+z-2}\right)= \\
& =\beta \sigma^{2}\left(1+\rho+\rho^{2}+\ldots+\rho^{z-1}\right)+\rho^{z} \operatorname{COV}\left(s_{i}, w_{i, s}\right)
\end{aligned}
$$

Since $\operatorname{COV}\left(\mathrm{s}_{\mathrm{i}}, \mathrm{w}_{\mathrm{i}, \mathrm{s}}\right)=\operatorname{COV}\left(\mathrm{s}_{\mathrm{i}}, \alpha+\beta \mathrm{s}_{\mathrm{i}}+\rho \mathrm{w}_{\mathrm{i}, \mathrm{s}-1}+\mathrm{u}_{\mathrm{i}, \mathrm{s}}\right)=\beta \sigma^{2}+\operatorname{COV}\left(\mathrm{s}_{\mathrm{i}}, \rho \mathrm{w}_{\mathrm{i}, \mathrm{s}-1}+\mathrm{u}_{\mathrm{i}, \mathrm{s}}\right)$ and $\operatorname{COV}\left(\mathrm{s}_{\mathrm{i}}, \rho \mathrm{w}_{\mathrm{i}, \mathrm{s}-1}+\mathrm{u}_{\mathrm{i}, \mathrm{s}}\right)=0$ by assumption, then we get:

(5)

$$
\begin{aligned}
& \operatorname{COV}\left(s_{i}, w_{i, s+z}\right)=\beta \sigma^{2}\left(1+\rho+\rho^{2}+\ldots+\rho^{z-1}\right)+\rho^{z} \beta \sigma^{2}= \\
& =\beta \sigma^{2}\left(1+\rho+\rho^{2}+\ldots+\rho^{z}\right)
\end{aligned}
$$

Hence, using (3), it follows that:

(6) $\quad p \lim \beta_{\text {OLS }}=\beta+\rho \beta \sum \rho^{\mathrm{z}}$ 
where $\rho \beta \sum \rho^{\mathrm{z}}$ is the persistence bias. The conclusion is that the OLS estimator of the schooling coefficient in model (2) is biased upward if $\beta$ and $\rho$ are positive, with the bias increasing in both $\rho$ and $\mathrm{z}$.

As a matter of example, Figure 1 illustrates how the bias increases with $\mathrm{z}$ using $\rho=0.600$ and $\beta=0.030$ as simulation parameters.

\section{Is the persistence bias worrisome?}

It is interesting to discuss the magnitude of the persistence bias when estimating a simple static wage-schooling model with real data. Particularly, we find of interest to explore a well-known publically available dataset of US young workers, in which the persistence bias should be lower than in a standard dataset including older workers since the average potential experience $(\mathrm{z})$ is lower (as the average age is lower).

Specifically, in this paper, the data are taken from the National Longitudinal Survey of Youth (NLSY). The dataset contains observations on 545 males for the period of 1980-1987. To our knowledge, this dataset has been already used by Vella and Verbeek (1998), Wooldridge (2005) and Andini (2007; 2012), among others.

The summary statistics of the variables and their meaning are presented in Appendix. The dataset has four main advantages: it is a balanced panel (which avoids a number of econometric issues with unbalanced panels), it is publically available (making replication easier), it has been already used in the literature (making comparison with earlier studies possible) and it has been already cleaned up, such that the schooling variable is actually time-invariant.

The estimation results, obtained using the OLS estimator, are presented in Table 1. Column 1 presents the OLS estimates from model (1), the 'true' one. The coefficient of schooling $\beta$ is estimated at 0.034 , with the degree of earnings persistence $\rho$ estimated at 0.599. Column 2 provides the estimate of the schooling coefficient from model (2), which does not control for earnings persistence. As expected, the estimate of the schooling coefficient is well above the 'true' value of the coefficient. Indeed, the coefficient is estimated at 0.076 . The difference between 0.076 and 0.034 can be seen as a proxy of the persistence bias, under our assumptions. Since the average potential experience $(\mathrm{z}$ ) in the sample is 6.5 years, a 0.042 bias is perfectly in line with our theoretical prediction (see Figure 1) and its magnitude is non-negligible. 


\section{Does extending the control set cure the persistence bias?}

Columns 3 to 7 gradually extend the static model (2) to investigate whether the persistence bias can be somehow cured (reduced) by increasing the control set, i.e. by improving the explanatory power of the static model (2) and searching for 'substitutes' of the past wage.

For instance, column 3 proposes the classical Mincer specification which controls for potential experience and its square. However, the coefficient of schooling does not decrease, thus indicating that potential experience (age) is not a substitute for past wage. In contrast, the schooling coefficient increases to 0.102 .

Columns from 4 to 7 add a number of individual specific characteristics, both time-varying and constant, which increase the explained variability of wages, though not as much as just controlling for past wage. In particular, column 4 takes into account union membership, marital status, public-sector employment, race (whether the individual is Black or Hispanic) as well as presence of health disabilities. Column 5 adds information on the individual residence (whether the individual lives in the South, Northern Central or North East). In addition, the data provide information on whether the individual lives in a rural area or not. Columns 6 and 7 add detailed information on industry and occupation, respectively.

The key point in this section is that no static specification is able to provide a coefficient of schooling close to the 'true' one, estimated using model (1).

Finally, column 8 adds year fixed effects to model (2). They are found to be not jointly significant (p-value 0.232). In addition, the R-squared does not significantly improve. Hence, likewise the experience variables, year effects cannot be seen as substitutes for past wage. At best, year effects can be seen as substitutes for experience variables themselves. However, to keep a Mincerian-type specification, in the rest of this paper, we will continue keeping experience variables in the control set, thus excluding year effects. Hence, our full control set will be the one used in column 7 .

\section{Does controlling for unobserved heterogeneity and endogeneity matter?}

This section argues that disregarding earnings persistence is still problematic for the estimation of the schooling coefficient even if individual unobserved heterogeneity and endogeneity are taken into account. We will show that the persistence bias is a problem related to the estimation of a static wage-schooling model, regardless of whether this estimation is performed using the OLS estimator or alternative estimators. 
To make the point of this section, borrowing from Andini (2012; 2013), we will first present a method to obtain consistent estimates of both the schooling coefficient and the degree of earnings persistence when unobserved heterogeneity, endogeneity and earnings persistence are taken into account. The method is based on the GMM-SYS estimator by Blundell and Bond (1998). Then, we will focus on the OLS estimator which disregards both unobserved heterogeneity and endogeneity. Finally, we will discuss the main point of this section by considering the Hausman-Taylor estimator, which takes into account unobserved heterogeneity and endogeneity but disregards earnings persistence.

\section{$\underline{5.1 \text { GMM-SYS estimator }}$}

Of course, the estimate of the schooling coefficient in model (1) based on the OLS estimator cannot be taken as a good proxy of the 'true' value of the schooling parameter due to correlation between errors and lagged wage (Nickell bias) and/or between errors and schooling (ability and/or attenuation bias). Such correlation causes the OLS estimator of model (1) to be inconsistent.

Indeed, let us assume that the error term $\mathrm{u}_{\mathrm{i}, \mathrm{s}+\mathrm{z}+1}$ in model (1) would be better seen as the sum between individual-specific effects $c_{i}$ and a 'well-behaved' disturbance $v_{i, s+z+1}$, such that $u_{i, s+z+1}=c_{i}+v_{i, s+z+1}$ with $^{3}$ :

(A9)

$\operatorname{COV}\left(s_{i}, c_{i}\right) \neq 0$

(A10) $\operatorname{COV}\left(\mathrm{s}_{\mathrm{i}}, \mathrm{v}_{\mathrm{i}, \mathrm{s}+\mathrm{z}+1}\right)=0$

(A11) $\operatorname{COV}\left(\mathrm{w}_{\mathrm{i}, \mathrm{s}+\mathrm{z}}, \mathrm{v}_{\mathrm{i}, \mathrm{s}+\mathrm{z}+1}\right)=0$ $\forall \mathrm{i}$

$\forall \mathrm{i}, \mathrm{s}+\mathrm{z}$

$$
\forall \mathrm{i}, \mathrm{s}+\mathrm{z}
$$

In this case, we introduce two sources of bias for the OLS estimator applied to model (1). The first one is assumption (A9) which implies that assumptions (A1) and (A8) do not hold true any more. The second one is that $w_{i, s+z}$ turns out to be correlated with $c_{i}$, making assumption (A2) invalid.

\footnotetext{
${ }^{3}$ For simplicity, we avoid reporting a couple of additional standard assumptions about $\mathrm{v}_{\mathrm{i}, \mathrm{s}+\mathrm{z}+1}$.
} 
Under the above new reasonable assumptions, Andini (2012; 2013) has shown that consistent $^{4}$ estimates for $\rho$ and $\beta$ are obtained using the GMM-SYS estimator by Blundell and Bond (1998), i.e. by using the following equations as a system:

$$
\Delta \mathrm{w}_{\mathrm{i}, \mathrm{s}+\mathrm{z}+1}=\rho \Delta \mathrm{w}_{\mathrm{i}, \mathrm{s}+\mathrm{z}}+\Delta \mathrm{v}_{\mathrm{i}, \mathrm{s}+\mathrm{z}+1}
$$

$$
\mathrm{w}_{\mathrm{i}, \mathrm{s}+\mathrm{z}+1}=\alpha+\beta \mathrm{s}_{\mathrm{i}}+\rho \mathrm{w}_{\mathrm{i}, \mathrm{s}+\mathrm{z}}+\mathrm{c}_{\mathrm{i}}+\mathrm{v}_{\mathrm{i}, \mathrm{s}+\mathrm{z}+1}
$$

and using $\mathrm{w}_{\mathrm{i}, \mathrm{s}+\mathrm{z}-1}$ and $\Delta \mathrm{w}_{\mathrm{i}, \mathrm{s}+\mathrm{z}-1}$ as instruments for (7) and (8), respectively.

Of course, the use of $\Delta \mathrm{w}_{\mathrm{i}, \mathrm{s}+\mathrm{z}-1}$ and further lags as instruments is the key assumption to identify the schooling coefficient and it has the advantage to be easily testable. In particular, the additional orthogonality conditions imposed by the level equation (8) must pass the Difference-in-Hansen test.

A further requirement is that the level-equation instruments should not be weak. This may happen in presence of non-stationary variables. The latter is also an easily testable assumption. A test can be based on the estimation of an AR1 process (with constant term) for the variable in levels, again using the GMM-SYS estimator. A preliminary test can be based on the OLS estimator, which typically overestimates the autoregressive coefficient (see Blundell and Bond, 2000). For instance, in our sample, using the OLS estimator, the autoregressive coefficient of the AR1 log-wage process (with constant term) is estimated at 0.626 with p-value equal to 0.000 . Hence, it is likely that the true autoregressive coefficient of the log-wage process is well below the critical value of 1.000 .

Of course, if one or more variables are found to be non-stationary, they should be excluded from the set of level-equation instruments.

Using the full control set, the GMM-SYS estimator provides an estimate of the degree of earnings persistence $\rho$ equal to 0.174 and an estimate of the schooling coefficient $\beta$ equal to 0.102 , both significant at $1 \%$ level.

\footnotetext{
${ }^{4}$ One limitation of the approach proposed by Andini (2012; 2013) is that selection is not considered. An extension of the approach including a participation equation keeping into account problems of self-selection into the labor market, such as those typically occurring with females, would be an interesting topic for future research.
} 


\section{$\underline{5.2 \text { OLS estimator }}$}

Taking the above estimates as the 'true' values of the corresponding parameters, it is interesting to discuss the biases implied by alternative estimators or models, with special attention to the coefficient of schooling.

The first thing to note is that Andini (2013) has already investigated the consequences for the OLS estimator of removing assumptions (A1), (A2) and (A8). In particular, using Belgian data, the author has pointed to an upward-biased estimate of the degree of earnings persistence and to a downward-biased estimate of the schooling coefficient.

Estimation with NLSY data in Table 2 confirms the above view. Column 1 reports the OLS estimates of model (1) with no controls. Column 2 adds all the controls considered in column 7 of Table 1, i.e. the full control set. The finding is that there is no big difference in the estimates of both $\beta$ and $\rho$. However, once individual unobserved heterogeneity and endogeneity are taken into account using the GMM-SYS estimator, the finding is different. Indeed, column 3 shows that the evidence confirms the above claim: the OLS estimator seems to overestimate the degree of earnings persistence and to underestimate the schooling coefficient (Table 2: column 2 vs. column 3).

\subsection{Hausman-Taylor estimator}

Yet, the key point in this section is not about the failure of the OLS estimator to account for individual unobserved heterogeneity, endogeneity and wage persistence. As stressed before, this issue has been one of those already investigated by Andini (2013). The key point here is to highlight how misleading can be the static-model estimation of the schooling coefficient, even when the control set is large and when both individual unobserved heterogeneity and endogeneity are taken into account. To this end, Table 3 presents some additional evidence comparing the 'true' estimate of the schooling coefficient based on the GMM-SYS estimator, again reported in column 3, with an estimate based on an important IV static-model estimator for panel data.

In particular, we consider an estimator which is typically used when time-invariant variables, such as schooling, are included in the explanatory set: the Hausman-Taylor (HT) estimator. As a benchmark, we also report an estimate of the schooling coefficient based on the Random Effects (RE) estimator.

The latter, used in column 1 , takes into account the longitudinal nature of the dataset and controls for individual unobserved effects under the assumption that they are uncorrelated with schooling and other explanatory variables. The former, used in 
column 2, additionally takes into account that some explanatory variables, including schooling, can be endogenous. Hence, the HT estimator takes both unobserved heterogeneity and endogeneity into account.

In all the columns of Table 3, the control set used is the full one. In particular, in the HT estimation, HLTH is taken as time-varying exogenous, BLACK and HISP are taken as time-invariant exogenous, SCHOOL is taken as time-invariant endogenous, and all the other variables in the full control set are taken as time-varying endogenous. The identification is based on the standard HT approach. For instance, the mean value of HLTH is used as instrument for SCHOOL.

Focusing on the HT estimation, the conclusion seems to be that again, likewise the OLS case, disregarding earnings persistence can be problematic. Indeed, the coefficient of schooling based on the HT estimator more than doubles the 'true' one (Table 3: column 2 vs. column 3).

A simple intuition for this result based on a static IV approach is as follows. Let us suppose that a researcher worries about a possible correlation between $u_{i, s+z+1}$ and $s_{i}$, but the role played by the past wage in model (1) is disregarded, i.e. the researcher assumes that $\rho=0$ while this hypothesis does not hold true. The standard and simplest IV practice is to find an instrument $g$ such that $\operatorname{COV}\left(\mathrm{g}_{\mathrm{i}}, \mathrm{s}_{\mathrm{i}}\right) \neq 0$ (for instance, the schooling years of the father of the individual i). In this case, it is easy to show that:

$$
\operatorname{plim} \beta_{I V}=\beta+\frac{\operatorname{COV}\left(g_{i}, u_{i, s+z+1}\right)}{\operatorname{COV}\left(g_{i}, s_{i}\right)}+\frac{\operatorname{COV}\left(g_{i}, \rho w_{i, s+z}\right)}{\operatorname{COV}\left(g_{i}, s_{i}\right)}
$$

Even if the researcher is able to find an instrument satisfying $\operatorname{COV}\left(\mathrm{g}_{\mathrm{i}}, \mathrm{u}_{\mathrm{i}, \mathrm{s}+\mathrm{z}+1}\right)=0$, the standard IV assumption, the IV estimator will still be inconsistent ${ }^{5}$ as $\operatorname{COV}\left(g_{i}, s_{i}\right) \neq 0$ implies $\operatorname{COV}\left(g_{\mathrm{i}}, \rho \mathrm{w}_{\mathrm{i}, \mathrm{s}+\mathrm{z}}\right) \neq 0$. This is trivial because $\mathrm{w}_{\mathrm{i}, \mathrm{s}+\mathrm{z}}$ is correlated with $\mathrm{s}_{\mathrm{i}}$.

The IV inconsistency result is also important for the experimental literature since, as stressed by Carneiro et al. (2006, p. 2), the IV method "is the most commonly used method of estimating $\beta$. Valid social experiments or valid natural experiments can be

\footnotetext{
${ }^{5}$ Another source of bias for the IV estimator in static models is the presence of heterogeneous returns to schooling, i.e. the case in which the schooling coefficient is not the same across individuals. There is an extensive literature on this topic with recent important contributions by Pedro Carneiro, James Heckman and Edward Vytlacil, among others. In this paper, we have not explored the intersection between heterogeneous returns and earnings persistence. However, it is an interesting topic for future research.
} 
interpreted as generating instrumental variables”. Yet, the autoregressive nature of wages is typically not taken into account in the experimental literature.

The good news for static-model users is that the GMM-SYS estimate of the schooling coefficient seems to be in line with the RE estimate (column 1 vs. column 3). More interestingly, the static Mincer model in column 3 of Table 1 seems to provide a very good proxy for the 'true' coefficient (0.102), suggesting that, once a quadratic function of experience is accounted for, the OLS estimator may benefit from the possibility that persistence, ability, attenuation and omitted-variable biases compensate each other. Although we are sceptical about this possibility (as a systematic compensation is very unlikely), we believe that this finding is worth further investigation. Nevertheless, as argued by Andini (2013), the coefficient of schooling from a static model (regardless of how it is estimated) cannot be interpreted as 'the return to schooling in terms of observed wages'.

\section{Conclusions}

This paper adds to the literature by providing several novel findings which highlight the importance of taking earnings persistence into account when estimating wage-schooling models. A formal expression for the persistence bias of the OLS estimator of the schooling coefficient is provided. The bias is found to be non-negligible in NLSY data. Extensions of the control set in a static wage-schooling model do not seem to reduce the bias. Problems with the estimation of the schooling coefficient in a static model accounting for individual unobserved heterogeneity and endogeneity are also discussed. Overall, the findings support the dynamic approach to the estimation of wage-schooling models recently proposed by Andini (2012; 2013).

\section{Highlights}

- A simple static wage-schooling model is considered

- The persistence bias of the OLS estimator for the schooling coefficient is defined

- The bias is found to be non-negligible in NLSY data

- The bias cannot be cured by extending the control set

- The bias is still problematic in a static model accounting for individual unobserved heterogeneity and endogeneity 


\section{References}

Andini, C. (2007) Returns to education and wage equations: a dynamic approach. Applied Economics Letters, 14(8): 577-579.

Andini, C. (2012) How well does a dynamic Mincer equation fit NLSY data? Evidence based on a simple wage-barganing model. Empirical Economics, doi 10.1007/s00181-012-0581-5.

Andini, C. (2013) Earnings persistence and schooling returns. Economics Letters, 118(3): 482-484.

Blundell, R.W., Bond, S.R. (1998) Initial conditions and moment restrictions in dynamic panel data models. Journal of Econometrics, 87(1): 115-143.

Blundell, R.W., Bond, S.R. (2000) GMM estimation with persistent panel data: an application to production functions. Econometric Reviews, 19(3): 321-340.

Card, D. (2001) Estimating the return to schooling: progress on some persistent econometric problems. Econometrica, 69(5): 1127-1160.

Carneiro, P., Heckman, J., Vytlacil, E. (2006) Estimating marginal and average returns to education. Available at: http://www.ucl.ac.uk/ uctppca/school_all_2006-1030b_mms.pdf (accessed: 13 Jan. 2013)

Griliches, Z. (1977) Estimating the returns to schooling: some econometric problems. Econometrica, 45(1): 1-22.

Vella, F., Verbeek, M. (1998) Whose wages do unions raise? A dynamic model of unionism and wage rate determination for young men. Journal of Applied Econometrics, 13(2): 163-183.

Wooldridge, J.M. (2005) Simple solutions to the initial conditions problem in dynamic, nonlinear panel data models with unobserved effects. Journal of Applied Econometrics, 20(1): 39-54. 
Figure 1

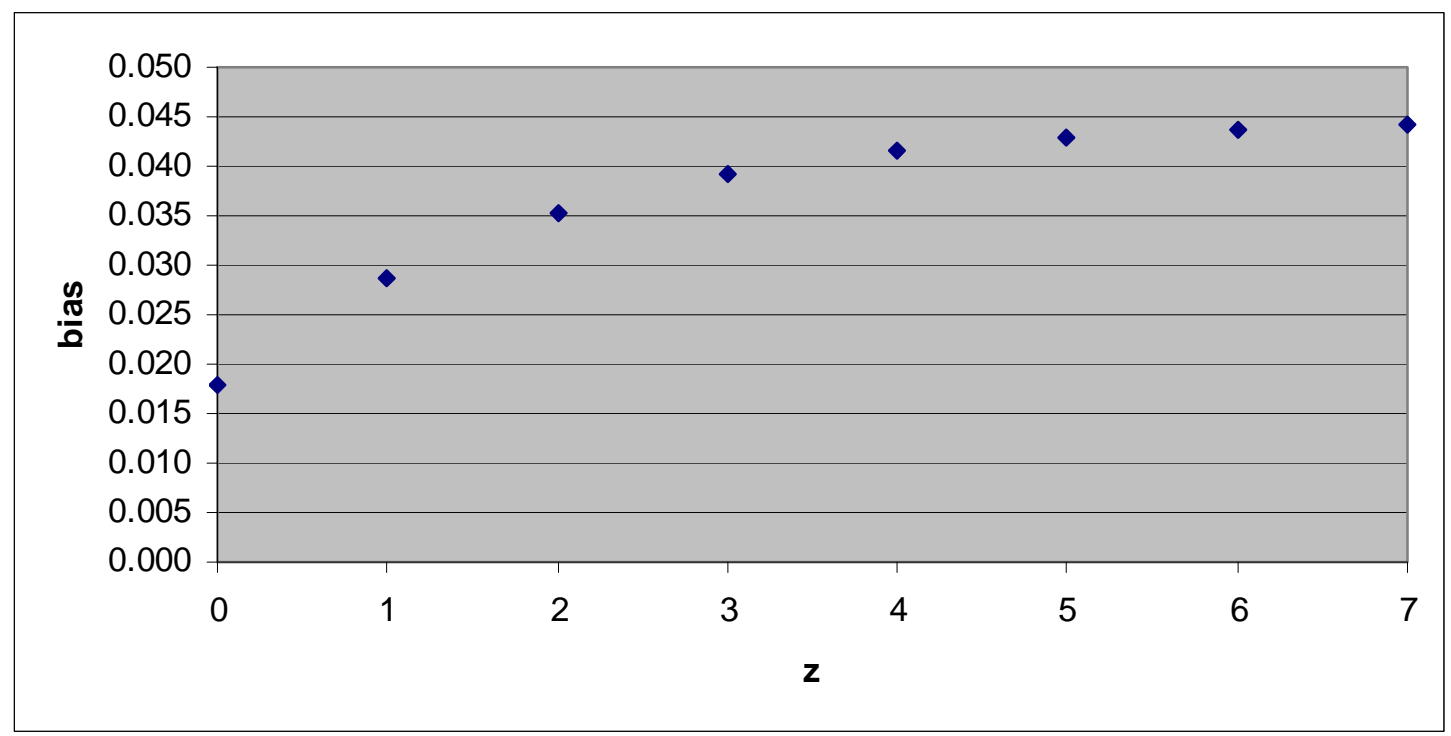

Simulation parameters: $\rho=0.600$ and $\beta=0.030$ 
Table 1

\begin{tabular}{|c|c|c|c|c|c|c|c|c|}
\hline & (1) & $(2)$ & (3) & (4) & (5) & (6) & $(7)$ & $(8)$ \\
\hline & OLS & OLS & OLS & OLS & OLS & OLS & OLS & OLS \\
\hline & Model (1) & Model (2) & Model (2) & Model (2) & Model (2) & Model (2) & Model (2) & Model (2) \\
\hline Control set & & & Ext 1 & Ext 2 & Ext 3 & Ext 4 & Full & Full + YE \\
\hline SCHOOL & $\begin{array}{c}0.034 * * * \\
(0.004)\end{array}$ & $\begin{array}{c}0.076 * * * \\
(0.004)\end{array}$ & $\begin{array}{c}0.102 * * * \\
(0.004)\end{array}$ & $\begin{array}{c}0.099 * * * \\
(0.004)\end{array}$ & $\begin{array}{c}0.093 * * * \\
(0.004)\end{array}$ & $\begin{array}{c}0.090 * * * \\
(0.004)\end{array}$ & $\begin{array}{c}0.078 * * * \\
(0.004)\end{array}$ & $\begin{array}{c}0.073^{* * *} \\
(0.005)\end{array}$ \\
\hline L.WAGE & $\begin{array}{c}0.599 * * * \\
(0.026)\end{array}$ & & & & & & & \\
\hline Observations & 3,815 & 4,360 & 4,360 & 4,360 & 4,360 & 4,360 & 4,360 & 4,360 \\
\hline R-squared & 0.429 & 0.064 & 0.148 & 0.187 & 0.204 & 0.264 & 0.278 & 0.280 \\
\hline $\begin{array}{l}\text { Controls } \\
\text { added to } \\
\text { model (2) } \\
\text { in previous } \\
\text { column }\end{array}$ & & & $\begin{array}{c}\text { EXPER } \\
\text { EXPER2 }\end{array}$ & $\begin{array}{l}\text { UNION } \\
\text { PUB } \\
\text { MAR } \\
\text { BLACK } \\
\text { HISP } \\
\text { HLTH }\end{array}$ & $\begin{array}{c}\mathrm{S} \\
\mathrm{NC} \\
\mathrm{NE} \\
\text { RUR }\end{array}$ & $\begin{array}{c}\text { MIN } \\
\text { CON } \\
\text { TRAD } \\
\text { TRA } \\
\text { FIN } \\
\text { BUS } \\
\text { PER } \\
\text { ENT } \\
\text { MAN } \\
\text { PRO }\end{array}$ & $\begin{array}{l}\text { OCC1 } \\
\text { OCC2 } \\
\text { OCC3 } \\
\text { OCC4 } \\
\text { OCC5 } \\
\text { OCC6 } \\
\text { OCC7 } \\
\text { OCC8 }\end{array}$ & $\begin{array}{l}\text { YEAR80 } \\
\text { YEAR81 } \\
\text { YEAR82 } \\
\text { YEAR83 } \\
\text { YEAR84 } \\
\text { YEAR85 } \\
\text { YEAR86 }\end{array}$ \\
\hline
\end{tabular}

Excluded categories: AG, OCC9 and YEAR87

Robust standard errors in parentheses

*** $\mathrm{p}<0.01,{ }^{* *} \mathrm{p}<0.05,{ }^{*} \mathrm{p}<0.1$ 
Table 2

\begin{tabular}{lccc}
\hline & $(1)$ & $(2)$ & $(3)$ \\
\hline & $\begin{array}{c}\text { OLS } \\
\text { Model (1) }\end{array}$ & $\begin{array}{c}\text { OLS } \\
\text { Model (1) } \\
\text { Control set }\end{array}$ & $\begin{array}{c}\text { GMM-SYS } \\
\text { Model (1) } \\
\text { Full }\end{array}$ \\
SCHOOL & & & \\
& $0.034^{* * *}$ & $0.037^{* * *}$ & $0.102^{* * *}$ \\
L.WAGE & $(0.004)$ & $(0.004)$ & $(0.028)$ \\
& $0.599^{* * *}$ & $0.503^{* * *}$ & $0.174^{* * *}$ \\
& $(0.026)$ & $(0.028)$ & $(0.031)$ \\
Observations & & & \\
R-squared & 3,815 & 3,815 & 3,815 \\
& 0.429 & 0.469 & \\
IUH accounted & & & Yes \\
Endogeneity accounted & No & No & Yes \\
Persistence accounted & Yo & Yes & Yes \\
Number of individuals & & & 545 \\
Number of instruments & & & 171 \\
ABAR1 test (p-value) & & & 0.000 \\
ABAR2 test (p-value) & & & 0.307 \\
Hansen test for all & & & \\
instruments (p-value) & & & 0.246 \\
Difference-in-Hansen test & & & \\
for level equation (p-value) & & & \\
\hline
\end{tabular}

Robust standard errors in parentheses

$* * * \mathrm{p}<0.01,{ }^{* *} \mathrm{p}<0.05,{ }^{*} \mathrm{p}<0.1$ 
Table 3

\begin{tabular}{|c|c|c|c|}
\hline & (1) & (2) & (3) \\
\hline & RE & HT & GMM-SYS \\
\hline & Model (2) & Model (2) & Model (1) \\
\hline Control set & Full & Full & Full \\
\hline SCHOOL & $0.090 * * *$ & 0.220 & $0.102 * * *$ \\
\hline & $(0.008)$ & $(0.172)$ & $(0.028)$ \\
\hline L.WAGE & & & $0.174 * * *$ \\
\hline & & & $(0.031)$ \\
\hline Observations & 4,360 & 4,360 & 3,815 \\
\hline IUH accounted & Yes & Yes & Yes \\
\hline Endogeneity accounted & No & Yes & Yes \\
\hline Persistence accounted & No & No & Yes \\
\hline Number of individuals & 545 & 545 & 545 \\
\hline Number of instruments & & & 171 \\
\hline ABAR1 test (p-value) & & & 0.000 \\
\hline ABAR2 test (p-value) & & & 0.307 \\
\hline Hansen test for all & & & \\
\hline instruments (p-value) & & & 0.246 \\
\hline $\begin{array}{l}\text { Difference-in-Hansen test } \\
\text { for level equation ( } p \text {-value) }\end{array}$ & & & 0.178 \\
\hline
\end{tabular}

Robust standard errors in parentheses

*** $\mathrm{p}<0.01,{ }^{* *} \mathrm{p}<0.05,{ }^{*} \mathrm{p}<0.1$ 


\section{Appendix. Sample descriptive statistics for NLSY data}

The data are taken from the National Longitudinal Survey of Youth. The dataset contains observations on 545 males for the period of 1980-1987. The statistics of the variables and their meaning are as follows:

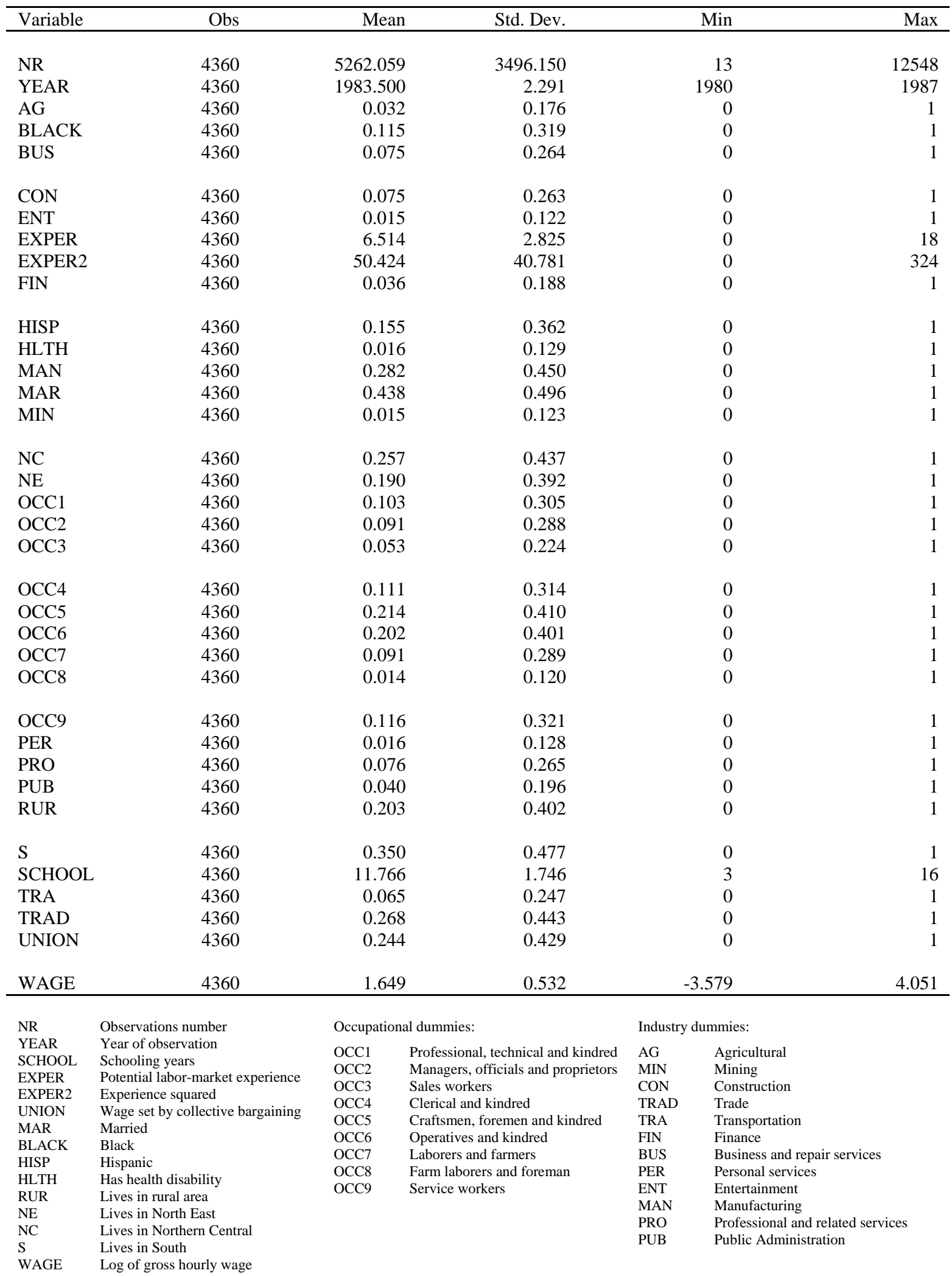

